\title{
Development of electrically conductive and anisotropic gel-coat systems using CNTs
}

\author{
Atike Ince Yardimci ${ }^{\mathrm{a}, *}$, Metin Tanoglu ${ }^{\mathrm{b}}$, Yusuf Selamet ${ }^{\mathrm{a}}$ \\ a Department of Physics, Izmir Institute of Technology, Urla, Izmir 35430, Turkey \\ ${ }^{\mathrm{b}}$ Department of Mechanical Engineering, Izmir Institute of Technology, Urla, Izmir 35430, Turkey
}

\section{A R T I C L E I N F O}

\section{Article history:}

Received 15 July 2012

Accepted 20 August 2012

Available online 22 November 2012

\section{Keywords:}

Carbon nanotubes

Chemical vapor deposition

Gel-coat

3-roll mill

Electrically anisotropic

\begin{abstract}
A B S T R A C T
Electrical conductivity of an unsaturated thermoset polyester based gel-coat system containing $0.05 \mathrm{wt} . \%$ of carbon nanotubes (CNTs) was investigated. The CNTs used were synthesized by chemical vapor deposition method by methane decomposition and Raman characterization showed that they were mostly single walled and high quality. To disperse CNTs in the gel-coat resin, 3-roll milling technique was used. It was found that as the CNTs are added to gel-coat system, resistivity value decreases significantly while neat gel-coat showed a high resistivity. By the application of an AC electrical field during curing process, it was attempted to align CNTs in the gel-coat resin and an electrically anisotropic polymer was obtained.
\end{abstract}

(C) 2012 Elsevier B.V. All rights reserved.

\section{Introduction}

Carbon nanotubes (CNTs) have high potential to be used in many applications due to special properties since their first observation by Iijima in 1991 [1]. High aspect ratio, Young modulus, tensile strenght, thermal and electrical conductivity are some of excellent properties of the CNTs [2]. Due to their high Young modulus and low weigth, they take part in high strength composite materials, interconnections, and functional devices in molecular electronics [3].

There are three main methods to produce CNTs, i.e. arc discharge, laser vaporization and chemical vapor deposition (CVD) methods [4]. Among these, CVD method is suitable for mass production. In this method an energy source such as a plasma, a resistive heater or a furnace is used to transfer energy to a gas phase carbon precursor and carbon deposition on metal catalysts results in carbon nanotube formation.

For new composites, CNTs excellent properties offer exciting opportunities. Fiber reinforced composites are employed in increasing applications such as wind turbine blades, automotive parts, and military applications. In the application of polymer composites, a top coating layer called or gel-coat is applied to prevent composites surfaces under service conditions and to provide decorative properties. Incorporation of a conductive gel-coat layer

\footnotetext{
* Corresponding author.

E-mail addresses: atikeince@iyte.edu.tr (A. Ince Yardimci), metintanoglu@iyte.edu.tr (M. Tanoglu), yusufselamet@iyte.edu.tr (Y. Selamet).
}

on the composite part is a great importance, as an example, for lightning of a wind blade and for anti-static behavior for a composite part. Because of the utilization of CNTs, the capacity of load transfer between the matrix and fibers can be increased. Recently, polymer/CNT composites are one of the hot topic because of their unique mechanical, surface and multi-functional properties, and strong interactions with the matrix resulting from the nano-scale microstructure and extremely large interfacial area. However, dispersion and alignment of CNTs in the matrix have significant effect on the final composite properties because the as-grown CNTs are often held together in bundles because of very strong van der Waals interactions [9]. There are several techniques to disperse CNTs in polymer matrices, such that optimum physical blending, in situ polymerization and chemical functionalization [10]. An alternative novel route, 3-roll milling technique utilized [11] in this study was used for dispersion of CNTs with the thermosetting resin. This technique provides intensive shear forces on the CNTs for their dispersion homogeneously within thermoset resin while it prevents ruptures and damages of CNTs.

A large number of polymers such as vinyl ester [5], epoxy [6], polyacrilonitrile [7], polypropylene [8] were used together with CNTs to synthesize nanocomposites. To our knowledge, there is no work in the literature to prepare conductive gel-coat system with CNTs. This study is the first to develop electrically conductive and anisotropic gel-coat systems that can be used as a top conducting layer on fiber reinforced composites. Due to the application of an AC electrical field CNTs were attempted to be aligned along a specific direction and obtain anisotropy in terms of electrical conductivity. 


\section{Experimental}

In this study, CNT growth experiments were performed at atmospheric pressure on $\mathrm{Co}-\mathrm{Mo} / \mathrm{MgO}$ catalyst. Firstly, a catalyst pretreatment took place with $\mathrm{H}_{2}$ gas flow at $150 \mathrm{sccm}$ for $1 \mathrm{~h}$ at $850^{\circ} \mathrm{C}$ to prevent amorphous carbon formation and to provide the reduction from metal oxide catalyst to metal catalyst which are more suitable for CNT growth. After reaching to $1000^{\circ} \mathrm{C}$ temperature, $50 \mathrm{sccm} \mathrm{CH}$ gas flow was started to initiate CNT growth. $\mathrm{H}_{2}$ continued to flow during CNT growth. Growth process took place $40 \mathrm{~min}$, then $\mathrm{CH}_{4}$ flow was turned off. CNTs was remained within the furnace to room temperature. Carbon nanotubes (CNTs) were used as nanofillers within the corresponding resin blend. Firstly $0.05 \mathrm{wt}$.\% of CNTs were dispersed in gel-coat by shear intensive blending via 3-roll milling technique. To polymerize gel-coat resin, cobalt naphtanate (CoNAP) and methyl ethyl ketone peroxide (MEKP) were introduced to the system as accelerator and initiator, with a ratio of 0.2 and $1 \mathrm{wt} . \%$, respectively. The resin suspensions were allowed to cure at room temperature followed by a post curing at $120^{\circ} \mathrm{C}$ for $2 \mathrm{~h}$, respectively.

To align the CNTs within the polymer matrix, CNT/resin suspensions were exposed to sinusoidal AC electric field of $400 \mathrm{~V} / \mathrm{cm}$ during curing by utilization of parallel aluminum plates. The samples were subsequently cut and contacted in the directions parallel and perpendicular to the direction of the applied electric field to assess the anisotropy of electrical conductivity in the nanocomposites. Two point technique was used to measure $I-V$ characteristics of composites. Contacts were obtained by coating samples with gold using a mask and a wire was used to create a gap with $17.5 \mu \mathrm{m}$.

\section{Results and discussions}

The morphology of CNTs was observed by the scanning electron microscopy (SEM). As seen from Fig. 1, as grown CNTs were of high quality. However, some tangled tubes were seen.

Raman spectra of CNTs are given in Fig. 2. Raman spectroscopy is generally used to study the quality of CNTs. It gives information about number of walls, the presence of crystalline and amorphous carbon and diameter of CNTs can be determined with the Raman spectroscopy. There are two main first order peaks are observed in Raman spectroscopy of the CNTs prepared in this work. The first one is the D peak and observed around $1300 \mathrm{~cm}^{-1}$ for excitation He-Ne laser, or at $1350 \mathrm{~cm}^{-1}$ for an $\mathrm{Ar}$ ion laser. This peak shows the presence of defects. The other one is the $G$ peak and observed at about $1580 \mathrm{~cm}^{-1}$, which is related to the in-plane vibrations of the graphene sheet [12,13]. Therefore, ratios of the $D$ peak to the $G$ peak gives the amount of disorder within CNTs [14]. Raman spectra of the CNTs (Fig. 2) showed a significantly high $I_{\mathrm{G}} / I_{\mathrm{D}}$ ratio which means

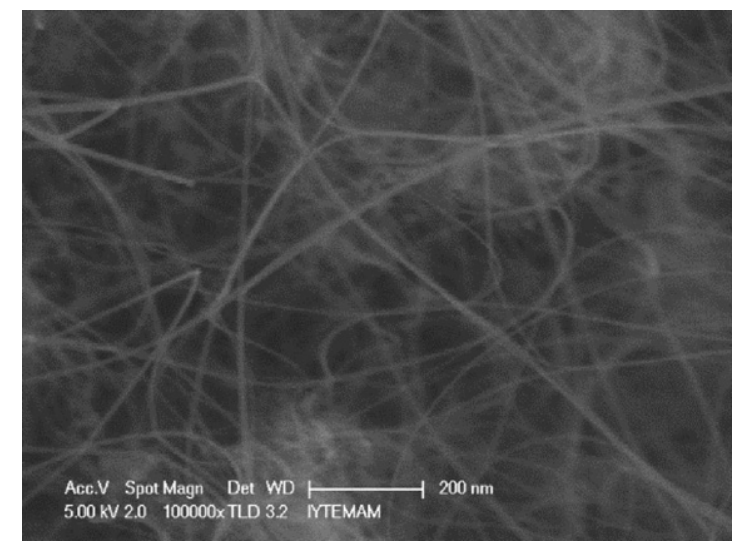

Fig. 1. SEM micrograph of CNT sample.

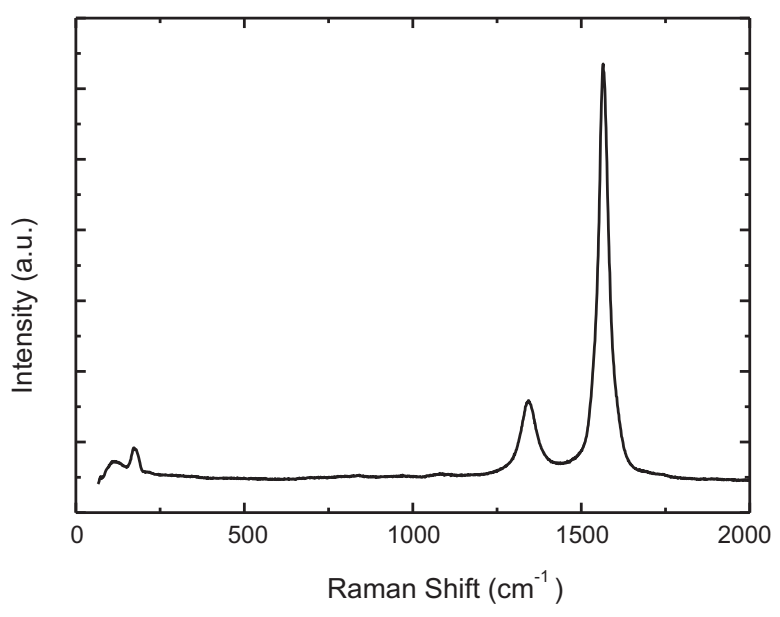

Fig. 2. Raman spectra of CNT sample.

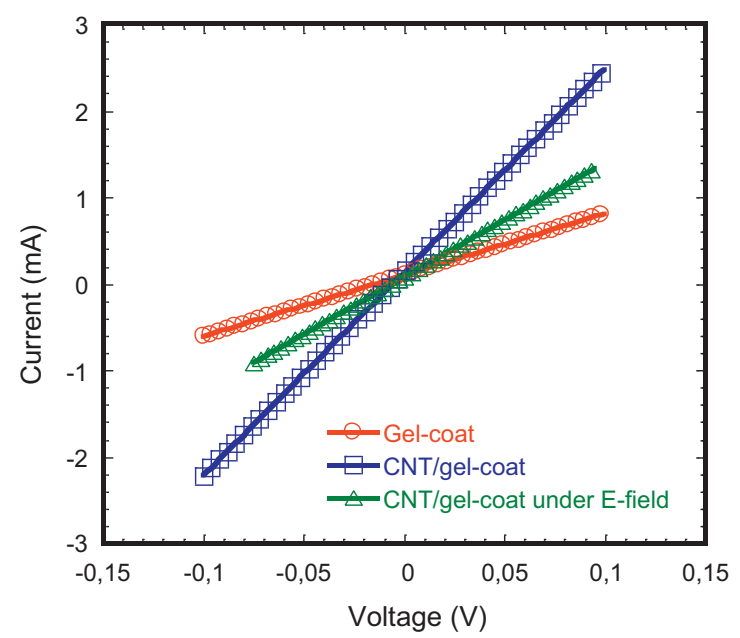

Fig. 3. Current-voltage graph of neat gel-coat, $0.05 \mathrm{wt}$ \% CNT added gel-coat and $0.05 \%$ CNT added gel-coat in the vertical direction after applying electrical field.

high graphitization and low disorder. RBM peaks, low energy peaks around 191 and $216 \mathrm{~cm}^{-1}$ are the radial breathing modes of CNTs [15], were observed for this sample, and it indicates that nanotubes used in this study were single walled.

$I-V$ measurements of samples (Fig. 3) showed that resistance of neat polymer was about $110 \Omega$. When $0.05 \%$ CNT was added to gel-coat polymer, its conductivity increased significantly and the resistance decreased to about $27 \Omega$. When CNTs were aligned under electrical field, it was observed that conductivity in the alignment direction of the CNTs increased and the conductivity normal to the alignment direction of CNTs is decreased. In normal direction, resistance was calculated from the slope of $I-V$ graph and it was found to be around $83 \Omega$. This indicates that an anisotropic gel-coat system can be prepared under applied electric field.

\section{Conclusions}

In this study, firstly synthesis of CNTs by methane decomposition catalytic chemical vapor deposition method on $\mathrm{Co}-\mathrm{Mo} / \mathrm{MgO}$ was carried out. As seen from SEM and Raman analysis obtained CNTs were of high quality single walled CNTs. At the second step electrical properties of gel-coat polymer was searched with and without adding $0.05 \%$ CNTs. CNTs were dispersed within gelcoat using 3-roll milling method. Electrical characterization of 
the samples were examined and it was seen that resistance of neat polymer was so high, however after adding CNTs, resistivity decreased and conductivity increased. To align CNTs an AC electrical field was applied and after application of electrical field conductivity in the vertical direction of CNTs decreased and an electrically anisotropic composite was obtained.

\section{References}

[1] S. Iijima, Nature 354 (1991) 56-58.

[2] J.-P. Salvetat, G.A.D. Briggs, J.M. Bonard, R.R. Bacsa, A.J. Kulik, T. Stockli, N.A. Burnham, L. Forro, Phys. Rev. Lett. 82 (1998).

[3] M. Su, B. Zheng, J. Liu, Chem. Phys. Lett. 322 (2000) 321-326.

[4] C. Baddour, C. Briens, Int. J. Chem. Reactor Eng. 3 (2005) 20-22.
[5] A.T. Seyhan, F.H. Gojny, M. Tanoglu, K. Schulte, Eur. Polym. J. 43 (2007) 2836-2847.

[6] K.T. Hsiao, J. Alms, S.G. Advani, Nanotechnology 14 (2003) 791.

[7] Y. Haihui, H. Lam, N. Titchenal, Y. Gogotsi, F. Ko, Appl. Phys. Lett. 85 (2004) 10.

[8] M.K. Seo, J.R. Lee, S.J. Park, Mater. Sci. Eng. A 404 (2005) 79-84.

[9] A. Thess, R. Lee, R.E. Smalley, Science 273 (1996) 483.

[10] X.-L. Xie, Y.-W. Mai, X.-P. Zhou, Mater. Sci. Eng. 49 (2005) 89-112.

[11] F.H. Gojny, K. Schulte, Compos. Sci. Technol. 34 (2004) 2303-2308.

[12] C. Singh, M.S.P. Shaffer, H. Windle, Carbon 41 (2003) 359-368.

[13] V. Shanov, Y.H. Yun, M.J. Schulz, J. Univ. Chem. Technol. Metall. 41 (4) (2006) 377-390.

[14] S.J. Tans, M.H. Devoret, H. Dai, A. Thess, R.E. Smalley, L.J. Geerligs, C. Dekker, Nature 386 (1997) 474-477.

[15] A. Rao, R. Richter, S. Bandow, B. Chase, P. Eklund, K.A. Williams, S. Fang, K.R. Subbaswamy, M. Menon, A. Thess, R. Smalley, G. Dresselhaus, M. Dresselhaus, Science 275 (1997) 187. 